\title{
Effect of muscle mass asymmetric between upper and lower limbs on the postural stability and shock attenuation during landing
}

\author{
Che-Cheong Ryew' ${ }^{1}$, Ae-Ri Lee'2, Seung-Hyun Hyun ${ }^{1, *}$ \\ 'Department of Kinesiology, College of Natural Science, Jeju National University, Jeju, Korea \\ 2Department of Leisure Sports Majors, Jeju Tourism College, Jeju, Korea
}

The aim of the study was to analyze the effect of muscle mass asymmetric between upper and lower limbs on postural stability and shock attenuation during landing. Twenty adults (without lower limb disorders and who could land from a $35-\mathrm{cm}$ height) participated in this study (mean age, $21.85 \pm 2.97$ years; mean height, $1.68 \pm 0.10 \mathrm{~m}$; mean weight: $68.64 \pm 17.36 \mathrm{~kg}$ ). Subjects performed one-leg landing from $36-\mathrm{cm}$ vertical heights. Ground reaction force components and medial-lateral, anterior-posterior, vertical and dynamic postural stability index were obtained from force platform recordings. We found that muscle mass in right limbs more increased than that of left limbs. Medial-lateral force, vertical force, vertical stability index, and dynamic postural stability in- dex in left leg showed higher value than that of right leg during landing. The asymmetry of muscle mass $(\%)$ and ground reaction force variables showed a similar correlation, including dynamic postural stability index $(r=0.316)$. These findings allow us to conclude that the factor of muscle mass asymmetric is a contributor to impulse control and dynamic postural stability index asymmetry. Therefore, knowledge of bilateral limbs asymmetry may provide insights into exercise rehabilitation and performance.

Keywords: Muscle mass, Shock attenuation, Asymmetry, Bilateral limbs, Exercise rehabilitation, Performance

\section{INTRODUCTION}

The shock experienced on body due to landings must be attenuated by several structures and mechanisms in the body including bone, synovial fluids, cartilage, soft tissues, joint kinematics and muscular activity (Lafortune et al., 1996; Nyland et al., 1994). Passively, shock attenuation is achieved by soft tissues and bone (Coventry et al., 2006). Actively, shock attenuation is achieved through eccentric muscle action. This active mechanism is thought to be far more significant than the passive mechanism in attenuating shock (Mizrahi and Susak, 1982).

Therefore basic mechanism controllable an angular momentum during human movement may be to generate muscle strength. The muscle strength generates ground reaction force to not only maintain and recover dynamic rebound but also accelerate a spe- cific body segment. But the assumption may support on the condition that motor performance and muscle strength have a symmetric relation. The assertion may be wrong when based on asymmetry (Bell et al., 2014).

Young adult in addition to sport athlete has the great extent of asymmetry in muscle strength between dominant and nondominant of lower leg (Lanshammar and Ribom, 2011). The flexors are weaker in the dominant leg and the extensors are weaker in the non-dominant leg. Thereby, the quotient between knee flexors and extensors is lower in the dominant leg.

Lean body mass which related directly with joint torque (Fukunaga et al., 2001), also contributes greatly to energy absorption at landing (Montgomery et al., 2012). Particularly Deficiency of muscular amount of lower limbs (thigh, shank, etc.) may result in reducing of motor ability and power (Bell et al., 2014). Thus repet-
${ }^{*}$ Corresponding author: Seung-Hyun Hyun (DD https://orcid.org/0000-0001-6348-6413 Department of Kinesiology, College of Natural Science, Jeju National University, 102 Jejudaehak-ro, Jeju 63243, Korea

E-mail: hshyun0306@jejunu.ac.kr

Received: April 9, 2019 / Accepted: May 30, 2019
This is an Open Access article distributed under the terms of the Creative Commons Attribution Non-Commercial License (http://creativecommons.org/licenses/by-nc/4.0/) which permits unrestricted non-commercial use, distribution, and reproduction in any medium, provided the original work is properly cited. 
itive activity of jumping, landing and cutting technique by one leg could still more deteriorate an extent of asymmetry in muscle amount (Bell et al., 2014).

Also injuries related with vertebrae parts can be occurred at rather low compressive load of $88 \mathrm{~N}$ (Granata and Marras, 1999; Punnett et al., 1991), but proper control of muscular activity can support stably against rather large vertebrae load (Quint et al., 1998; Wilke et al., 1995). But proper posture selection can control the neuromuscular system maintaining posture stability, which followed the compression force of inter-vertebrae on condition of asymmetric posture of $20^{\circ}$ increased by $21 \%$ (Granata and Wilson, 2001).

Like this, it was reported that difference of muscle strength between both side of body segment contribute greatly to control an exercise amount and impulse absorption. But it was not clear whether relationship between asymmetry of muscle amount and impulse absorption and posture stability is or not. Thus information on asymmetry between intersegments may provide insight ability on the injurious possibility, exercise rehabilitation and motor ability.

Consequently the aim of this study was to grasp quantitatively relationship between asymmetry in muscle amount and ground reaction force parameters both dominant and nondominant of lower leg. This study assumed that fine difference of muscle amount in both side of segment on the basis of analyzed material of 167 subjects (Bell et al., 2014) firstly will induce asymmetry on impulse force and an extent of posture stability and secondly positive correlation between posture stability and variables of impulse force (\%). Landing motion aligned in line with vertical direction was induced in order gravity effect to distribute evenly on center of gravity of body segment according to the assumption.

\section{MATERIALS AND METHODS}

\section{Subject}

Adult male and female without lower limb disorders and with all right dominant of leg $(n=20$; mean age, $21.85 \pm 2.97$ years; mean height, $1.68 \pm 0.10 \mathrm{~m}$; mean weight, $68.64 \pm 17.36 \mathrm{~kg}$ ) participated in the experiment. All participants agreed to the experimental procedures voluntarily.

\section{Experimental procedure}

All participants prior to an experiment carried out measurement of muscle amount using Inbody 720 (Biospace, Seoul, Korea) and executed enough warming-up exercise. Landing motion by only one leg (right or left) from vertical height of $35 \mathrm{~cm}$ performed randomly. Then landing procedure kept sight aligned with forward direction and positioned both hand on anterior superior iliac spine. Each experimental trial was defined until dynamic control was completed (static condition) after landing, and only 1 trial of 3-4 trials performed successfully was adapted for analysis. Collected sampling rate on GRF (AMTI-OR9-7, AMTI, Watertown, MA, USA) was set up at 1,000 $\mathrm{Hz}$. Landing motion was performed on bare foot to reduce data error from shoe material.

\section{Definition of analysis phase}

Dynamic postural stability was defined as individual's ability to maintain a balance of body posture during converting from dynamic to static condition (Goldie et al., 1989). Also time to stabilization was defined as necessitated time which ground reaction force generated at landing can keep up with within range of static condition

Therefore the time for stabilization may be occurred rather difference relative to individual's characteristics and experimental procedure regardless of calculation by dynamic postural stability index (DPSI) (Wikstrom et al., 2005). Thus, this study calculated time for stabilization applied on peak value from each direction of ground reaction force for clear interpretation of data (Hyun and Ryew, 2017).

$$
\begin{aligned}
& M L S I=\left.\sqrt{\left[\sum\left(0-x_{\max .}\right)^{2}\right.} / \text { number of data points }\right] \\
& A P S I=\left.\sqrt{\left[\sum\left(0-y_{\max .}\right)^{2}\right.} / \text { number of data points }\right] \\
&\left.V S I=\sqrt{\left[\sum\left(\text { bodyweight }-z_{\max .}\right)^{2}\right.} / \text { number of data points }\right] \\
& D P S I= \sqrt{\left[\sum\left(0-x_{\max .}\right)^{2}+\sum\left(0-y_{\max .}\right)^{2}+\sum\left(\text { bodyweight }-z_{\max .}\right)^{2} /\right.} \\
&\text { number of data points }]
\end{aligned}
$$

Medial-lateral (ML), anterior-posterior (AP), vertical (V), and DPSI mean that the higher an index value, the lower the stability, the lower an index value, and the higher the stability (Wikstrom et al., 2005). These indices mean square deviations assessing fluctuations around a 0 (zero) point, rather than standard deviation assessing fluctuations around a group mean.

\section{Analysis and process of data}

Then mean \pm standard deviation was processed on variables with PASW Statistics ver. 22.0 (IBM Co., Armonk, NY, USA) program and paired $t$-test. Change rate (\%) of each variables on muscle mass and landing posture was compared with Pearson correlation coefficients and set at $P<0.05$. 


\section{RESULTS}

Change of each muscle mass between upper and lower limbs are shown in (Table 1). Right muscle mass of upper and lower limbs showed more increased than that of left limbs, and showed significant $(P<0.05)$.

Change of ground reaction force variables during landing are shown in (Table 2). ML and peak vertical force at left leg showed significant difference with higher than that of right leg $(P>0.05)$. Also, vertical stability index and DPSI at left leg showed higher index than that of right leg and show significant difference $(P<$ 0.001).

Correlation calculated with change rate between muscle mass asymmetric and ground reaction force variables are shown in (Table 3). Change rate of upper arm muscle mass showed positive correlation of $r=0.562$ (A) with ML force, and $r=0.316$ (B) with vertical stability index, and $r=0.336(\mathrm{C})$ with DPSI. In addition, change rate of leg muscle mass and ML force showed a negative correlation of $r=-0.343$ (D).

Also, AP force and vertical force showed a positive correlation

Table 1. Results of muscle mass between both bilateral limbs (unit: $\mathrm{kg}$ )

\begin{tabular}{|c|c|c|c|c|c|}
\hline \multirow{2}{*}{ Section } & \multicolumn{2}{|c|}{ Bilateral limbs } & \multirow{2}{*}{$\%$} & \multirow{2}{*}{$t$} & \multirow{2}{*}{$P$-value } \\
\hline & Right & Left & & & \\
\hline Muscle mass of upper limbs & $2.56 \pm 0.95$ & $2.49 \pm 0.92$ & -2.73 & 3.699 & $0.002^{* *}$ \\
\hline Muscle mass of lower limbs & $8.20 \pm 2.23$ & $8.07 \pm 2.18$ & -1.59 & 2.500 & $0.022^{*}$ \\
\hline
\end{tabular}

Values are presented as mean \pm standard deviation.

${ }^{*} P<0.05$. ${ }^{*} P<0.01$.

Table 2. Results of kinetic variables between both legs during landing

\begin{tabular}{|c|c|c|c|c|c|}
\hline \multirow{2}{*}{ Section } & \multicolumn{2}{|c|}{ Bilateral legs } & \multirow{2}{*}{$\%$} & \multirow{2}{*}{$t$} & \multirow{2}{*}{$P$-value } \\
\hline & Right & Left & & & \\
\hline Medial-lateral force (N/BW) & $0.10 \pm 0.23$ & $-0.15 \pm 0.24$ & 50.00 & 2.808 & $0.011^{*}$ \\
\hline Anterior-posterior force (N/BW) & $0.36 \pm 0.27$ & $0.43 \pm 0.29$ & 19.44 & -0.92 & 0.369 \\
\hline Vertical force (N/BW) & $5.57 \pm 1.30$ & $6.40 \pm 1.16$ & 14.90 & -4.848 & $0.001^{* * *}$ \\
\hline Medial-lateral stability index & $1.99 \pm 1.08$ & $1.91 \pm 0.94$ & -4.02 & 0.292 & 0.773 \\
\hline Anterior-posterior stability index & $5.56 \pm 1.48$ & $6.34 \pm 2.14$ & 14.03 & -1.481 & 0.155 \\
\hline Vertical stability index & $36.80 \pm 7.64$ & $43.28 \pm 7.10$ & 17.61 & -5.99 & $0.001^{* * *}$ \\
\hline Dynamic postural stability index & $44.48 \pm 8.56$ & $51.54 \pm 9.24$ & 15.87 & -5.152 & $0.001^{* * *}$ \\
\hline
\end{tabular}

Values are presented as mean \pm standard deviation.

${ }^{*} P<0.05 .{ }^{* * *} P<0.001$.

Table 3. Correlation results using the asymmetry between muscle mass and ground reaction force variables ( $)$ )

\begin{tabular}{|c|c|c|c|c|c|c|c|c|}
\hline Section & Lower limbs & M-L force & A-P force & Vertical force & $\mathrm{MLSI}$ & APSI & VSI & DPSI \\
\hline Upper limbs & 0.091 & $0.562^{*}(A)$ & 0.027 & -0.099 & 0.175 & 0.110 & $0.316^{*}(\mathrm{~B})$ & $0.336^{*}(C)$ \\
\hline Lower limbs & & -0.163 & -0.120 & -0.291 & $-0.343^{*}$ (D) & -0.070 & 0.199 & 0.075 \\
\hline M-L force & & & 0.094 & 0.057 & 0.017 & 0.005 & 0.067 & 0.043 \\
\hline A-P force & & & & $0.335^{*}(E)$ & -0.009 & 0.029 & 0.027 & 0.053 \\
\hline Vertical force & & & & & 0.208 & 0.101 & 0.211 & 0.251 \\
\hline MLSI & & & & & & -0.092 & 0.123 & 0.282 \\
\hline APSI & & & & & & & 0.288 & $0.526^{*}(F)$ \\
\hline VSI & & & & & & & & $0.930^{* *}(\mathrm{G})$ \\
\hline
\end{tabular}

M-L, medial-lateral; A-P, anterior-posterior; MLSI, medial-lateral stability index; APSI, anterior-posterior stability index; VSI, vertical stability index; DPSI, dynamic postural stability index.

Regression equation: $\mathrm{A}: \mathrm{y}=53.25 \mathrm{x}-1.0385, R^{2}=0.3093 ; \mathrm{B}: \mathrm{y}=1.5825 \mathrm{x}+0.2383, R^{2}=0.1057: \mathrm{C}: \mathrm{y}=1.6879 \mathrm{x}+0.2158, R^{2}=0.13 ; \mathrm{D}: \mathrm{y}=-7.0577 \mathrm{x}-0.0103, R^{2}=0.1264 ; \mathrm{E}: \mathrm{y}=0.0072 \mathrm{x}+$ $0.1588, R^{2}=0.1124 ; \mathrm{F}: \mathrm{y}=0.8925 \mathrm{x}-0.0046, R^{2}=0.8617 ; \mathrm{G}: \mathrm{y}=0.1509 \mathrm{x}+0.1434, R^{2}=0.2715$.

${ }^{*} P<0.05 .{ }^{*} P<0.01$. 
of $r=0.335$ (E). DPSI showed positive correlation of $r=0.526$ (F) with AP stability index, and $r=0.930(\mathrm{G})$ with vertical stability index.

\section{DISCUSSION}

Jumping and landing motion for human is commonly locomotion for human (Kang, 2018; Kim, 2018; Ryew and Hyun, 2018; Titton and Franchini, 2017), but it was not clear whether asymmetry of muscle amount of both leg effects performance of landing motion or not. The study was to investigate relationship between fine difference of muscle amount and controllability of ground reaction force of both legs during landing motion.

Biomechanical difference between lower extremities of dominant or nondominant during physical activity has relation with physiological and anatomical asymmetry, but no specific evidence (Niu et al., 2011). But in results of assumption testimony, asymmetry of muscle amount showed more increased tendency in right hand-leg than left extremities. It showed similar result that asymmetry of muscle amount of thigh showed 84 samples (50\%) of $0 \%-5 \%$ range, 56 samples $(34 \%)$ of $5 \%-10 \%$ range, 22 sample (13\%) of 10\%-15\% range, 5 (3\%) of over $15 \%$ range, meanwhile asymmetry of muscle amount of shank showed 127 samples (76\%) of $0 \%-5 \%$ range, 37 samples $(22 \%)$ of $5 \%-10 \%$ range and 3 samples (2\%) of 10\%-15\% range respectively (Bell et al., 2014).

ML and vertical ground reaction force variables at landing of one leg showed more increased pattern in left leg than that of right leg, and also higher index in left leg in both dynamic postural stability and vertical postural stability. Thus the first assumption that asymmetry of muscle amount in both sides of leg may induce asymmetry in impulse force and an extent of posture stability, was accepted partially.

The study showed that larger impulse force was occurred when landed by left leg formed with less muscle amount relatively, but impulse controlling time was decreased reversely. Fortunately the participants performed safe landing by one leg of $1-3$ times during experiment, but a cumulated stress might increase an injury possibility on tissue like cartilage, ligament, and skeletal (Yeow et al., 2009). Because repetitive landing motion during sport situation and physical activity occurs, strategy for asymmetric impulse absorption and stabilization may contribute greatly to reduction of injury occurrence of lower limb.

But this study could not present the relative contribution on injury occurrence because it was difficult for us to grasp quantita- tively the parameters of neuromuscular control (Walsh et al., 2012), muscle strength (Montgomery et al., 2012), cross sectional area of muscle (Fukunaga et al., 2001), joint coordination (Lees et al., 2004) etc. Also parameters like length of lower limb, tendon properties and tendon length could contribute to force controllability (Bell et al., 2014). But these parameters had little possibility of influencing on asymmetry between both sides of limbs (Bell et al., 2014).

Because it was sufficiently explained on asymmetry of muscle amount between both sides of lower limbs, if additional quantitative parameters like neuromuscular control, muscle strength, cross sectional area of muscle, joint coordination etc. secured more clear understanding on asymmetry and mechanism on injury prevention could be presented.

Thus the second assumption that relation between posture stability and variables of impulse force (\%) will have positive correlation was accepted partially. Similar correlation between ground reaction force components of three directions and stability index had not relation with asymmetry of muscle amount, but rather due to calculation method of stability and direction of force generation. Thus more remarkable variables were relationship among asymmetry of muscle amount and ML force and ML and vertical DPSI. That is, asymmetry of muscle amount between both sides of leg segments have an effect on parallel force, thus may increase a uniaxial load on lower limbs and vertebrae. Thus the result of correlation among variables at landing by one leg could refer to possibility of slipping and falling injury. Consequently it was assumed that asymmetry factor between both sides of lower limbs contributed greatly to controllability of impulse force and dynamic posture stability. These results may be provided insight to exercise rehabilitation and motor performance.

\section{CONFLICT OF INTEREST}

No potential conflict of interest relevant to this article was reported.

\section{ACKNOWLEDGMENTS}

This research was supported by the 2019 scientific promotion program funded by Jeju National University

\section{REFERENCES}

Bell DR, Sanfilippo JL, Binkley N, Heiderscheit BC. Lean mass asymme- 
try influences force and power asymmetry during jumping in collegiate athletes. J Strength Cond Res 2014;28:884-891.

Coventry E, O'Connor KM, Hart BA, Earl JE, Ebersole KT. The effect of lower extremity fatigue on shock attenuation during single-leg landing. Clin Biomech (Bristol, Avon) 2006;21:1090-1097.

Fukunaga T, Miyatani M, Tachi M, Kouzaki M, Kawakami Y, Kanehisa H. Muscle volume is a major determinant of joint torque in humans. Acta Physiol Scand 2001;172:249-255.

Goldie PA, Bach TM, Evans OM. Force platform measures for evaluating postural control: reliability and validity. Arch Phys Med Rehabil 1989; 70:510-517.

Granata KP, Marras WS. Relation between spinal load factors and the high-risk probability of occupational low-back disorder. Ergonomics 1999;42:1187-1199.

Granata KP, Wilson SE. Trunk posture and spinal stability. Clin Biomech (Bristol, Avon) 2001;16:650-659.

Hyun SH, Ryew CC. A comparison of ground reaction force components according to the foothold heights in 16-t truck during downward step. J Exerc Rehabil 2017;13:722-727.

Kang S. Difference of neuromuscular responses by additional loads during plyometric jump. J Exerc Rehabil 2018;14:960-967.

Kim JH. The short-term health promotion effect of the whole-body vibration exercise program for the improvement of the agility, the quick reaction ability, and the flexibility of the students aspiring for the physical education-affiliated departments in Korea. J Exerc Rehabil 2018; 14:758-764.

Lafortune MA, Lake MJ, Hennig EM. Differential shock transmission response of the human body to impact severity and lower limb posture. J Biomech 1996;29:1531-1537.

Lanshammar K, Ribom EL. Differences in muscle strength in dominant and non-dominant leg in females aged 20-39 years--a populationbased study. Phys Ther Sport 2011;12:76-79.

Lees A, Vanrenterghem J, De Clercq D. The maximal and submaximal vertical jump: implications for strength and conditioning. J Strength Cond Res 2004 ;18:787-791.

Mizrahi J, Susak Z. Analysis of parameters affecting impact force attenua- tion during landing in human vertical free fall. Eng Med 1982;11:141147.

Montgomery MM, Shultz SJ, Schmitz RJ, Wideman L, Henson RA. Influence of lean body mass and strength on landing energetics. Med Sci Sports Exerc 2012;44:2376-2383.

Niu W, Wang Y, He Y, Fan Y, Zhao Q. Kinematics, kinetics, and electromyogram of ankle during drop landing: a comparison between dominant and non-dominant limb. Hum Mov Sci 2011;30:614-623.

Nyland JA, Shapiro R, Stine RL, Horn TS, Ireland ML. Relationship of fatigued run and rapid stop to ground reaction forces, lower extremity kinematics, and muscle activation. J Orthop Sports Phys Ther 1994;20: 132-137.

Punnett L, Fine LJ, Keyserling WM, Herrin GD, Chaffin DB. Back disorders and nonneutral trunk postures of automobile assembly workers. Scand J Work Environ Health 1991;17:337-346.

Quint U, Wilke HJ, Shirazi-Adl A, Parnianpour M, Löer F, Claes LE. Importance of the intersegmental trunk muscles for the stability of the lumbar spine. A biomechanical study in vitro. Spine (Phila Pa 1976) 1998;23:1937-1945.

Ryew CC, Hyun SH. The contribution analysis of knee compression bandage and arm swing control on maximum horizontal distance in standing long jump. J Exerc Rehabil 2018;14:239-243.

Titton A, Franchini E. Postactivation potentiation in elite young soccer players. J Exerc Rehabil 2017;13:153-159.

Walsh M, Boling MC, McGrath M, Blackburn JT, Padua DA. Lower extremity muscle activation and knee flexion during a jump-landing task. J Athl Train 2012;47:406-413.

Wikstrom EA, Tillman MD, Smith AN, Borsa PA. A new force-plate technology measure of dynamic postural stability: the dynamic postural stability index. J Athl Train 2005;40:305-309.

Wilke HJ, Wolf S, Claes LE, Arand M, Wiesend A. Stability increase of the lumbar spine with different muscle groups. A biomechanical in vitro study. Spine (Phila Pa 1976) 1995;20:192-198.

Yeow CH, Lee PV, Goh JC. Effect of landing height on frontal plane kinematics, kinetics and energy dissipation at lower extremity joints. J Biomech 2009;42:1967-1973. 